\title{
Isolation and maintenance of Batrachochytrium salamandrivorans cultures
}

\author{
Kristyn A. Robinson ${ }^{1}$, Kenzie E. Pereira ${ }^{2}$, Molly C. Bletz ${ }^{3}$, Edward Davis Carter ${ }^{4}$, \\ Matthew J. Gray ${ }^{4}$, Jonah Piovia-Scott ${ }^{5}$, John M. Romansic ${ }^{5}$, Douglas C. Woodhams ${ }^{3}$, \\ Lillian Fritz-Laylin ${ }^{1, *}$ \\ ${ }^{1}$ Department of Biology, University of Massachusetts, Amherst, MA 01003, USA \\ ${ }^{2}$ Department of Biology, Duquesne University, Pittsburgh, PA 15282, USA \\ ${ }^{3}$ Department of Biology, University of Massachusetts, Boston, MA 02125, USA \\ ${ }^{4}$ Department of Forestry, Wildlife, and Fisheries, University of Tennessee, Knoxville, TN 37996, USA \\ ${ }^{5}$ School of Biological Sciences, Washington State University, Vancouver, WA 98686, USA
}

\begin{abstract}
Discovered in 2013, the chytrid fungus Batrachochytrium salamandrivorans (Bsal) is an emerging amphibian pathogen that causes ulcerative skin lesions and multifocal erosion. A closely related pathogen, $B$. dendrobatidis $(B d)$, has devastated amphibian populations worldwide, suggesting that Bsal poses a significant threat to global salamander biodiversity. To expedite research into this emerging threat, we seek to standardize protocols across the field so that results of laboratory studies are reproducible and comparable. We have collated data and experience from multiple labs to standardize culturing practices of Bsal. Here we outline common culture practices including a medium for standardized Bsal growth, standard culturing protocols, and a method for isolating Bsal from infected tissue.
\end{abstract}

KEY WORDS: Chytridiomycosis $\cdot$ Amphibian disease $\cdot$ Emerging infectious disease $\cdot$ Life cycle Management

\section{INTRODUCTION}

Two species of chytrid fungus, Batrachochytrium dendrobatidis ( $B d_{i}$ Longcore et al. 1999) and B. salamandrivorans (Bsal; Martel et al. 2013), are the etiological agents of chytridiomycosis, a necrotic skin disease that is a major driver of the global decline in amphibian biodiversity (Scheele et al. 2019).

$B d$ was the first pathogen known to cause chytridiomycosis. The isolation of $B d$ in 1999 (Longcore et al. 1999) prompted vigorous efforts to understand its basic biology, geographic distribution, and the major factors promoting its spread and persistence (Berger et al. 1998, Woodhams \& Alford 2005, Lips 2016). Bd can infect a broad range of amphibian hosts, including frogs (Scheele et al. 2019), salamanders (Chatfield et al. 2012), and caecilians (Gower et al. 2013). It has

\footnotetext{
*Corresponding author: lfritzlaylin@umass.edu
}

been detected on every amphibian-inhabited continent and is presumed to have spread through the globalized trade of infected amphibians originating from endemic areas (Schloegel et al. 2012). The impact of $B d$ has been particularly pronounced for frogs, and has already driven at least 90 species to extinction (Kilpatrick et al. 2010, O'Hanlon et al. 2018, Scheele et al. 2019). Although many questions remain unanswered, the ability to isolate $B d$ from amphibians and maintain $B d$ cultures in the laboratory (Garner et al. 2016, Cook et al. 2018, Waddle et al. 2018) has advanced the understanding of its epidemiology and enabled the evaluation of mitigation strategies to prevent further declines and extinctions (Waddle et al. 2018, Watts et al. 2019, Woodhams et al. 2020).

Bsal was identified in 2013 following a sudden crash in fire salamander Salamandra salamandra popula-

(C) The authors 2020. Open Access under Creative Commons by Attribution Licence. Use, distribution and reproduction are unrestricted. Authors and original publication must be credited. 
tions in the Netherlands (Martel et al. 2013). While both frogs and salamanders can be infected by experimental exposure to Bsal (Stegen et al. 2017), only post-metamorphic salamanders appear to develop ulcerative skin lesions and multifocal erosion (Van Rooij et al. 2015). Non-Asian salamanders belonging to the family Salamandridae are especially susceptible to $B s a l$ and often experience high levels of disease and mortality (Martel et al. 2013).

Bsal is thought to have originated and naturally coexist in amphibian communities throughout Asia without causing apparent harm (Laking et al. 2017). Like $B d, B s a l$ is predicted to continue to spread by way of the pet trade of amphibians carrying subclinical Bsal infections (Sabino-Pinto et al. 2018, Yuan et al. 2018). The pet trade in both Europe and North America has been restricted to prevent the spread of Bsal infection, and efforts have been made to establish action plans to enact when and where Bsal is detected (Gray et al. 2015). Although Bsal has yet to be detected in the USA (Klocke et al. 2017), continued surveillance and collaboration between scientists and policymakers are needed to forestall the emergence of Bsal (Watts et al. 2019, Martel et al. 2020).

To prevent a Bsal panzootic with the potential to rapidly drive salamanders to extinction, we need to develop conservation and disease management strategies that are based on controlled laboratory research. The required research spans diverse fields, including herpetology, mycology, epidemiology, and molecular and cell biology. To enable new laboratories and researchers to quickly get started cultivating $B s a l$, and to promote the use of standard procedures across existing Bsal labs, we here provide an overview of practices for working with Bsal cultures. These methods, collated from disparate publications and collective experience, include recommended protocols for (1) culturing Bsal in liquid and solid media, (2) isolating specific Bsal life stages, and (3) extracting Bsal from infected tissue.

\section{BASIC CULTURING TECHNIQUES}

\subsection{Biosafety}

Bsal is an amphibian-specific pathogen and does not pose a significant risk to humans. To prevent the spillover of Bsal outside of the laboratory, it is imperative that high levels of biosafety (at least the equivalent of United States Biosafety Level 2; https://www.cdc.gov/ cpr/infographics/biosafety.htm) are observed when working with live cultures. This includes conducting all culture work in a biosafety cabinet. The following resources may be useful for working with your institution to develop a detailed biosafety protocol: Burnett et al. (2009) outline general biosafety practices when working with pathogenic microorganisms, and Van Rooij et al. (2017) review chemical disinfectants and necessary exposure times for killing Bsal.

\subsection{Life cycle}

Like $B d$ and other zoosporic fungi, the life cycle of $B s a l$ is characterized by a free-swimming infective stage known as a zoospore and stationary reproductive stage called a sporangium (Fig. 1). Although population genetic evidence suggests that $B d$ may be capable of both sexual and asexual reproduction (Morgan et al. 2007, Jenkinson et al. 2016), the production of asexual zoospores is presumably the primary reproductive mode for both $B d$ and Bsal. In vitro, zoospores give rise to thalli containing one (monocentric) or multiple (colonial) sporangia. Bsal sporangia have been reported to produce 2 types of infective spores: the motile zoospore described above, and a buoyant encysted spore that, in the wild, is hypothesized to float to the surface of aquatic habitats and aid in transmission (Martel et al. 2013, Stegen et al. 2017).

\subsection{Media}

Bsal grows well in both liquid and solid media (see Appendices $1 \& 2$ for formulations). While liquid medium results in more uniform growth and better sporulation, solid medium allows for the formation of colonies that are not easily dislodged from the agar surface, which can be advantageous for some applications. Solid medium is also best for shipping Bsal cultures because of the reduced potential for contamination.

To promote experimental consistency across laboratories, we suggest the adoption of a single, uniform growth medium. It is important to carefully consider what kind of medium to use, as this decision may influence aspects of $B s a l$ biology and growth as it does for $B d$ (Piotrowski et al. 2004; see Appendices 1 \& 2). We therefore estimated $B s a l$ growth rates in a variety of liquid media types by tracking the change in optical density over time (Fig. 2, significance determined using an overall 1-way ANOVA followed by a Tukey post hoc test, $\mathrm{p}<0.01$, performed in $\mathrm{R}$ v3.5.3, www. cran.r-project.org). While all tested media facilitated Bsal growth, the growth rates were highest in tryp- 


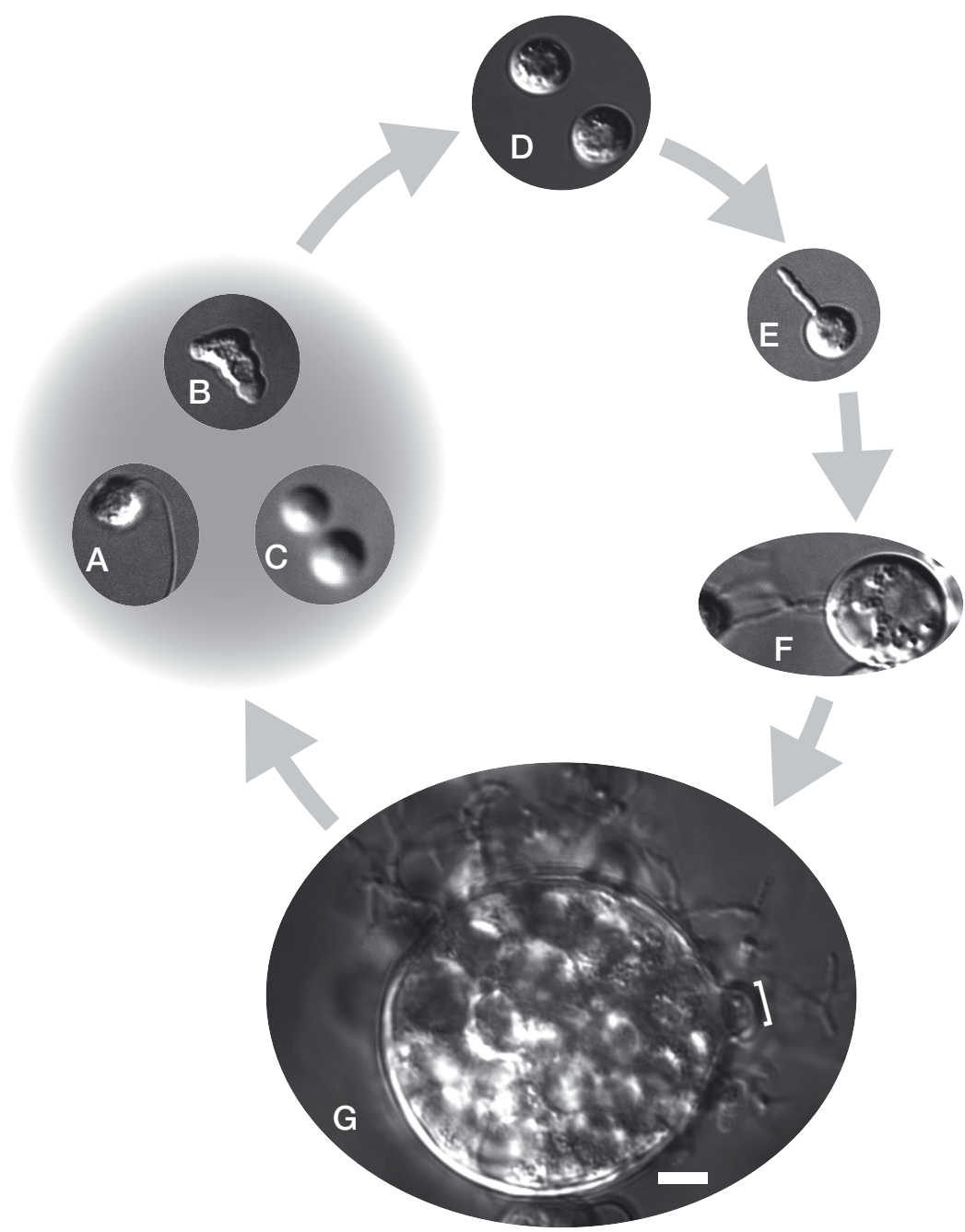

Fig. 1. In vitro life cycle of Batrachochytrium salamandrivorans (Bsal). (A) Motile zoospores can navigate through their environment using a posterior flagellum to swim and (B) amoeboid motility to crawl across surfaces. (C) Encysted spores have also been reported to float in media (Stegen et al. 2017). (D) Once a motile zoospore is ready to colonize, it will encyst and retract its flagellum. (E) Cysts develop one or several rhizoids. (F) Thalli (immature sporangia) increase in volume before maturation. (G) The mature sporangia produce zoospores internally and assemble a discharge tube (indicated by bracket). Zoospores are then released from the sporangia via discharge tube and begin the cycle again. Cells were imaged using a $40 \times$ air (C) and $100 \times$ oil objective (all others). Scale bar $=5 \mu \mathrm{m}$

tone-gelatin hydrosylate-lactose (TGhL) and tryptone media (Fig. 2B). Further testing validated the importance of tryptone in media but found no significant difference in Bsal growth rates in media with additional components (Fig. 2C). Although cultures grown in TGh, TGhL, TL, and tryptone all grew at equivalent rates, individual components may alter other aspects of Bsal biology outside of simple growth rates. Because of the widespread use of both TGhL and halfstrength TGhL, we recommend using half-strength TGhL medium to maintain Bsal cultures. If after fur- ther testing, Bsal grown in tryptone medium yields similar infection rates as cultures grown in TGhL, then the use of the simple medium would be preferred.

\subsection{Antibiotics}

While practicing sterile techniques should minimize fungal and bacterial contamination, some laboratories choose to include ampicillin and/or streptomycin in the culture medium (see Appendix 3). Although the use of antibiotics may provide additional protection against microbial contamination, antibiotics have been observed to alter behavior and gene expression in diverse eukaryotic cells (Neftel \& Hübscher 1987, Nygaard et al. 2015, Ryu et al. 2017). The effects of antibiotics on chytrid species in regard to cell metabolism and changes in gene expression have not been tested. We recommend that the experimental needs of the lab be carefully evaluated when deciding whether to supplement medium with antibiotics.

\subsection{Growth temperature}

Bsal grows well at $15^{\circ} \mathrm{C}$ and can be stored for weeks to months at $4^{\circ} \mathrm{C}$. $B s a l$ does not tolerate warmer temperatures (thermal maximum $=25^{\circ} \mathrm{C}$ ) and dies rapidly if left at room temperature for an extended period of time (Martel et al. 2013). We recommend purchasing an incubator capable of holding a steady below-room temperature before beginning to culture Bsal. Despite the thermal limitations of Bsal, proper biosafety procedures must be followed prior to disposing of Bsal cultures and generated wastes (see Section 2.1).

\section{SUBCULTURING}

Subculturing, also known as passaging, is the addition of cells from a previous culture to fresh medium (liquid or solid) to generate a new culture. We recom- 

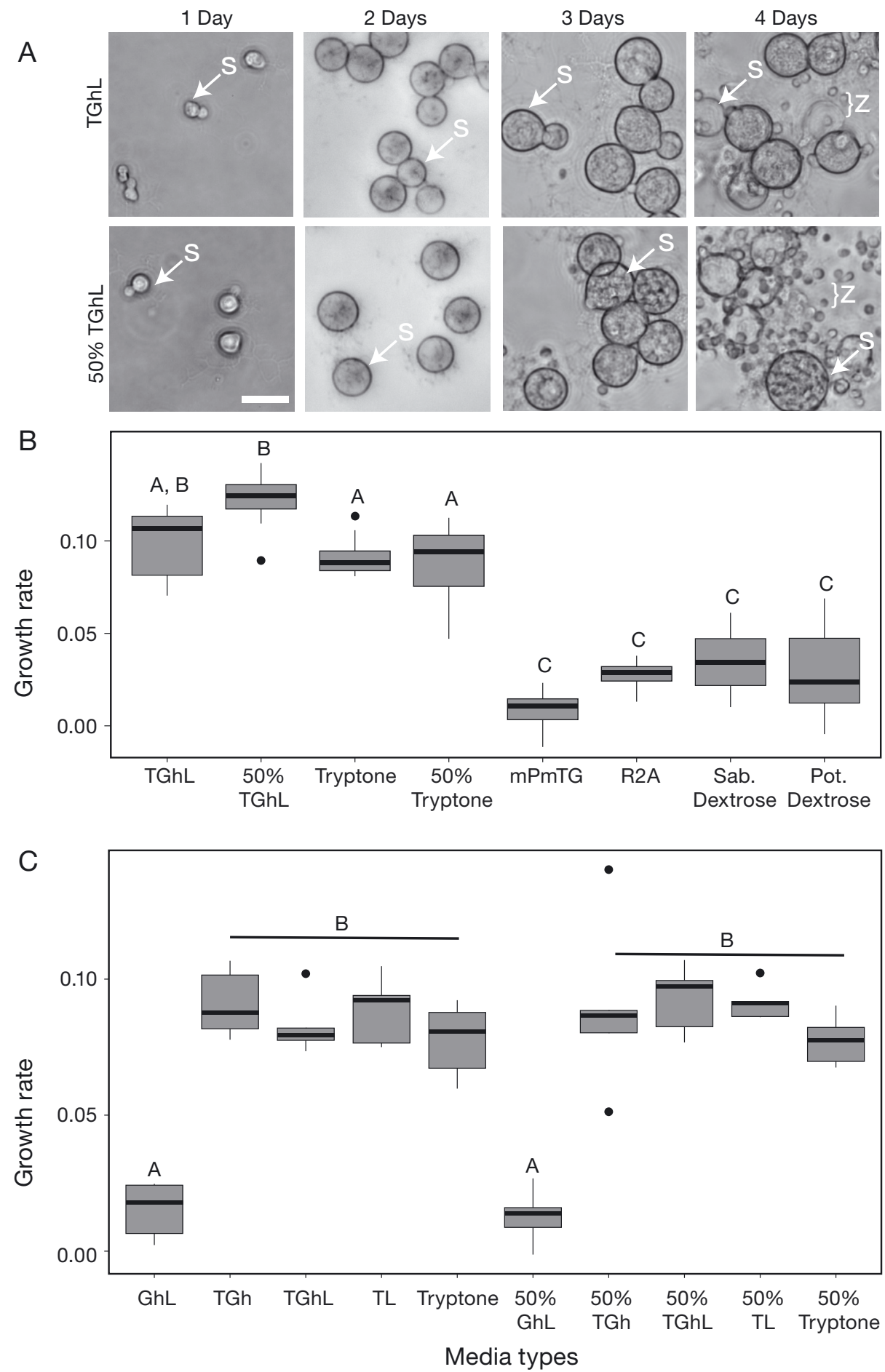

Fig. 2. Batrachochytrium salamandrivorans (Bsal) growth in different media types. (A) Bsal grown in half (50\%) and fullstrength TGhL liquid media for $4 \mathrm{~d}$. Most sporangia (s) grown in half-strength TGhL release zoospores (z) approximately $24 \mathrm{~h}$ earlier than sporangia grown in full-strength TGhL. Scale bar $=25 \mu \mathrm{m}$. (B) Growth in different media types and (C) subsets of TGhL media components was compared using a growth assay: Bsal zoospores $\left(5 \times 10^{4}\right.$ well $\left.^{-1}\right)$ were inoculated into the wells of a 96-well tissue culture-treated plate containing the indicated media. Growth was measured daily by optical density (OD) using an Omega FluorStar spectrophotometer at $492 \mathrm{~nm}$ for $5 \mathrm{~d}$. Growth rate was calculated as the slope of OD measurements through time. Growth rate significantly differed among media (ANOVA, $F_{8,62}=54.98, \mathrm{p}<0.001, \mathrm{R}$ v3.5.3). Bar: median; box: $25^{\text {th }}-75^{\text {th }}$ percentile (interquartile range, IQR); whiskers: $\max . / \mathrm{min} . \leq 1.5 \times$ IQR above/below box; dots: outliers. Treatments with different letters differ statistically from each other. Treatments with the same letter have statistically the same growth rate 
mend regular subculturing to maintain uniform and reproducible cultures. Regular subculturing also reduces variability between experiments by minimizing differences due to aging sporangia, depletion of nutrients, and the buildup of cell waste and cell debris. We recommend recording and including passage numbers in publications, as there is evidence that virulence of $B d$ can be altered after multiple passages in culture (Langhammer et al. 2013, Voyles et al. 2014, Refsnider et al. 2015, Lips 2016), and we suspect that the same is true for Bsal.

\subsection{Subculturing in liquid medium}

To subculture Bsal, an aliquot of mature culture is added to a clean sterile flask containing fresh medium that has been pre-chilled to $15^{\circ} \mathrm{C}$. The new culture flask is moved to the $15^{\circ} \mathrm{C}$ incubator and left to grow. Cultures inoculated with zoospores grow more reproducibly than cultures started from mixedstage cultures containing both zoospores and sporangia. Because tissue culture (TC)-treated flasks make it easy to separate zoospores that are suspended in liquid medium from sporangia which adhere tightly to the flask walls, we recommend growing Bsal in TC-treated, plug-sealed flasks.

Growing cultures at high densities can cause an accumulation of cell waste and deplete nutrients that may limit cell growth. Growth of Bsal at very high densities can result in an irrecoverable state of arrested growth characterized by sporangia that fail to mature and sporulate. To maintain high, but not overcrowded, cell densities, we routinely start liquid cultures using both 1:10 (1 part zoospore culture from the old flask to 9 parts fresh medium) and 1:20 ratios to ensure robust growth in at least 1 flask of cells. This technique results in a final concentration of around $3 \times 10^{4}$ zoospores $\mathrm{ml}^{-1}$ without having to count zoospores at each passage. To prevent the overgrowth of cultures, we recommend subculturing on a regular schedule. For example, growing at $15^{\circ} \mathrm{C}$ with half-strength $\mathrm{TGhL}$, we subculture at 1:20 ratio every $4 \mathrm{~d}$. We also recommend storing the old culture flask at $4^{\circ} \mathrm{C}$ for 1 to 2 wk as a backup in case the new culture becomes contaminated.

\subsection{Synchronizing liquid cultures}

A synchronous culture contains cells in the same growth stage and can be quite useful for experiments that require large numbers of zoospores. To fully syn- chronize a culture, we recommend adding 6 to $7 \times$ $10^{6}$ age-matched zoospores (see Section 4) suspended in half-strength TGhL liquid medium to a $75 \mathrm{~cm}^{2}$ TC-treated flask. Typically, a newly synchronized Bsal culture grown in this way will release zoospores 4 to 6 d later (see Section 4). In our experience, adding too many or too few zoospores results in a less synchronous culture.

\subsection{Subculturing on solid medium}

Bsal grows well on solid medium made of full or half-strength TGhL or $1 \%$ tryptone agar with or without added antibiotics (see Appendices 2 \& 3). While it is possible to subculture Bsal on solid medium using cells grown on a plate (plate to plate subculturing), we recommend subculturing on solid medium using liquid-grown cells (liquid to plate subculturing). We typically add $\sim 5 \times 10^{6}$ total zoospores harvested from liquid culture (see Section 4 ) to each agar plate pre-chilled to $15^{\circ} \mathrm{C}$. Sterilized glass beads or glass spreaders are then used to spread the zoospores evenly across the plate.

Mixed-stage cultures can also be used to inoculate solid medium and can be useful for rapidly producing large numbers of zoospores. First, use a sterile cell scraper to dislodge sporangia from the wall of the TC-treated flask and then gently swirl the flask to homogenize the culture. Add $1 \mathrm{ml}$ of the mixed culture to a pre-chilled agar plate and spread by tilting the plate side to side.

Once an agar plate has been inoculated with zoospores or a mixed stage culture, place plates agar side down at $15^{\circ} \mathrm{C}$ to allow the added liquid to completely soak into the agar (approximately $30 \mathrm{~min}$ ). To determine whether the liquid has been sufficiently absorbed, agar plates are observed while being tilted side to side. If a liquid sheen is present on the surface of the plate but no moving liquid is observed, then the plate is wrapped in parafilm, turned with the agar side up, and incubated at $15^{\circ} \mathrm{C}$ for the remainder of the growth period. If liquid freely moves across the plate, the liquid is given additional time to absorb. Grow until obvious colonies develop and zoospores can be seen using a microscope (Fig. 3). Because Bsal is sensitive to desiccation, agar plates should be carefully monitored to ensure they do not dry out. If plates do dry out, a humid chamber can be used to store plates in the incubator; a clean baking pan covered with aluminum foil along with a beaker of sterile water works well. 


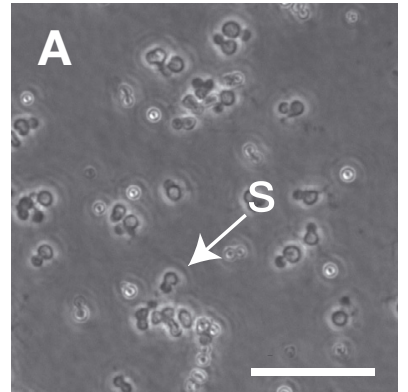

1 Day

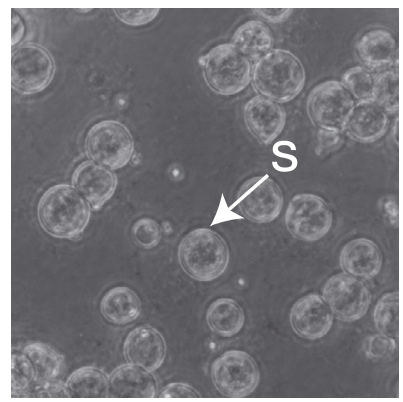

3 Days

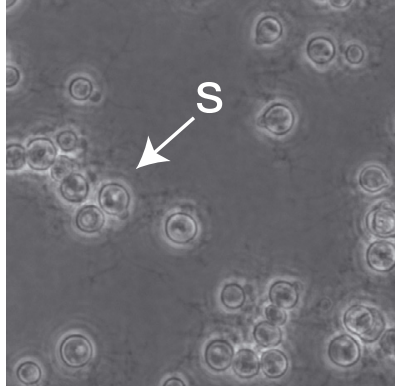

2 Days

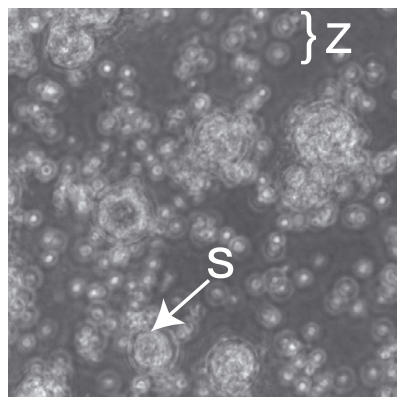

4 Days

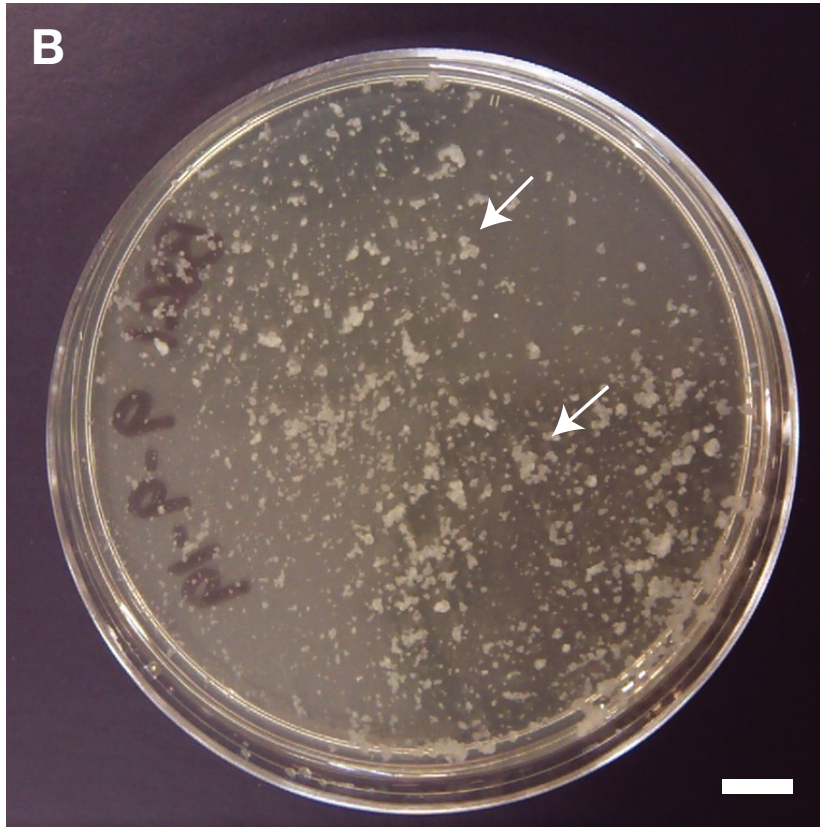

5 Days
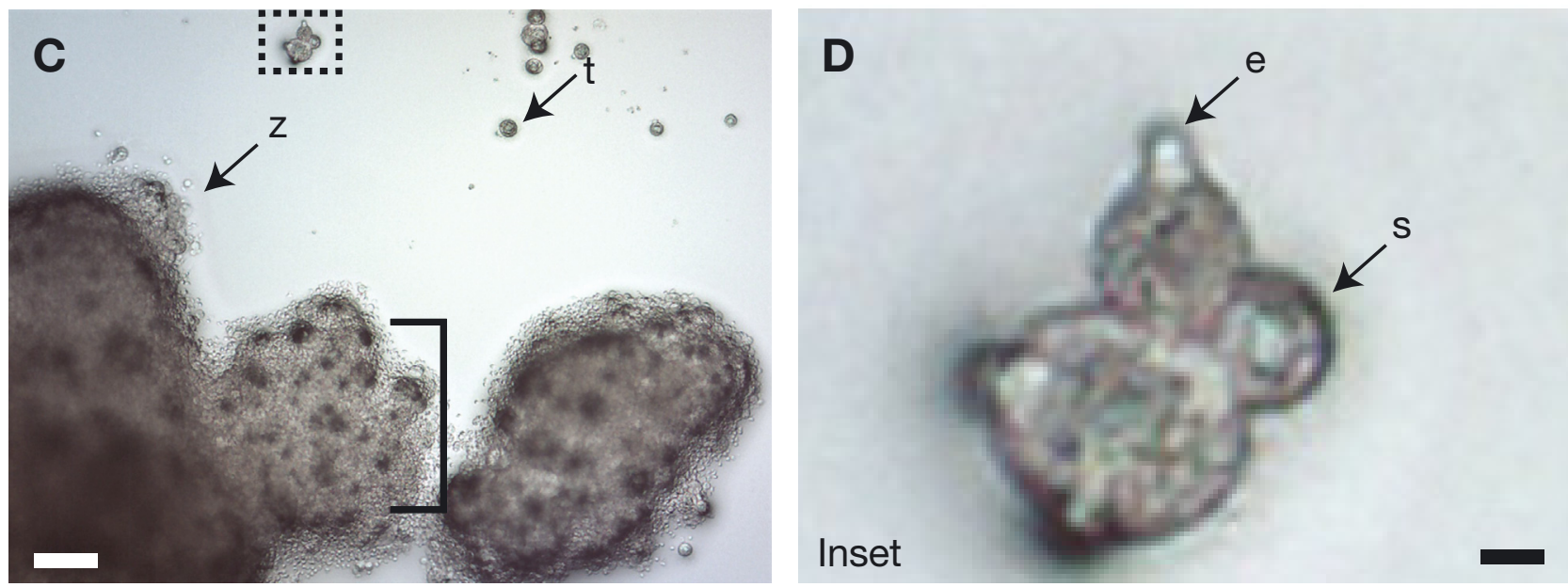

Fig. 3. Batrachochytrium salamandrivorans (Bsal) growth imaged on solid media agar plates. (A) Zoospores (z) were inoculated on half-strength TGhL plates with $1 \%$ agar and no antibiotics. Sporulation begins after $3 \mathrm{~d}$ of growth with robust zoospore release from sporangia (s) after $4 \mathrm{~d}$. Scale bar $=250 \mu \mathrm{m}$. (B) Growth on full-strength TGhL solid media with antibiotics after $4 \mathrm{~d}$. This plate was inoculated with a mixed-stage culture grown in a tissue culture-treated flask for 5 d. Colonies appear as translucent white smooth aggregations; examples are indicated by arrows. Scale bar $=10 \mathrm{~mm}$. (C) Bsal colonies grown on full-strength TGhL solid media with antibiotics after a $4 \mathrm{~d}$ incubation. Large gray structures represent aggregations (bracket) of maturing sporangia. Zoospores appear as small translucent spherical structures and are abundant at the perimeter of these aggregations, while larger spherical structures represent thalli (immature sporangia; t) and sporangia. Scale bar $=50 \mu \mathrm{m}$. (D) Inset from C (indicated by the dashed box). A discharge/exit tube (e) appears as a semi-translucent growth off the side of a sporangium. Scale bar $=5 \mu \mathrm{m}$. Note: To help researchers new to Bsal recognize healthy growing colonies on plates, we imaged by placing the petri dish directly on an inverted microscope. This is more efficient than making wet mounts but results in poorer image quality

\subsection{Handling contamination}

Proper sterile technique prevents most incidences of contamination (Coté 2001). Over the course of a culture's growth period, periodic gross and micro- scopic observations should be performed to verify that cultures remain healthy and uncontaminated. If available, we recommend using an inverted microscope which allows daily observation of the culture directly in the flask. It is worth noting that Bsal can 
develop biofilm-like aggregates when grown at high cell densities. Bacterial cells can be easily differentiated from Bsal based on differences in size (bacterial cell diameter $<2 \mu \mathrm{m}$; zoospore diameter $4-5.5 \mu \mathrm{m}$; sporangia diameter $<15.7 \mu \mathrm{m})$, and morphology. Bsal zoospores often develop germ tubes (Martel et al. 2013) and can adopt an ameboid morphology similar to $B d$ (Longcore et al. 1999, Fritz-Laylin et al. 2017) that when observed under a microscope might be mistakenly identified as a biological contaminant. If contamination is suspected and cannot be ruled out via microscopic examination, subculture to solid medium. Contamination of cultures grown on solid medium is more easily determined because of the morphological disparities between Bsal colonies and those of non-chytrid microbes (Fig. 3).

If a culture becomes contaminated, we recommend immediately disposing of the infected culture. Clearing Bsal from contaminants is time consuming and often unsuccessful. New cultures can be restarted from cultures stored at $4^{\circ} \mathrm{C}$ that show no signs of contamination or from a frozen stock (see Section 6).

\section{HARVESTING ZOOSPORES}

A synchronized liquid culture of Bsal can yield a vast quantity of zoospores from a single flask, with concentrations up to 2 to $8 \times 10^{6}$ zoospores $\mathrm{ml}^{-1}$. Therefore, we recommend that Bsal cultures grown in liquid culture medium are first synchronized prior to attempting to harvest zoospores (see Section 3.2). If a synchronized culture is not available, zoospores can be harvested from solid medium (see Sections 3.3 and 4.3). To determine whether a synchronized Bsal culture is suitable for harvesting, examine it under a microscope. If sporangia have developed discharge tubes or papillae (Fig. 1), and have released a few zoospores, the culture can be used for harvesting.

\subsection{General harvesting from liquid culture}

This method is used for harvesting large numbers of zoospores. To begin, remove half-strength TGhL medium from the flask and replace with $10 \mathrm{ml}$ of sterile Bonner's salts or fresh half-strength medium (see Appendix 1), depending on the subsequent use of the zoospores. The flask is then returned to $15^{\circ} \mathrm{C}$ for $5 \mathrm{~h}$ to overnight to allow zoospores to collect in the chosen liquid. After the incubation period, check for zoospore release using a microscope. If zoospores are present, collect the liquid medium from the flask and, if de- sired, filter to remove any remaining sporangia (see Section 4.4). Determine the concentration of zoospores using a hemocytometer (see Section 4.5), and use for downstream applications, such as exposure experiments, growth inhibition assays, and/or subculturing.

\subsection{Age-matched harvesting from liquid culture}

For some applications, it can be helpful to start with a precisely age-matched population of zoospores. This protocol is similar to the general harvesting outlined above but uses a much shorter collection time. Start with a synchronized culture grown in a TCtreated flask; when the sporangia in the culture are just beginning to release zoospores, pour out the medium from the side of the flask opposite to adhered sporangia to prevent dislodging sporangia from the flask wall. Rinse the remaining zoospores from the flask by adding $10 \mathrm{ml}$ of fresh medium by allowing it to flow gently across the sporangia and out of the flask. Sterile Bonner's salts or fresh halfstrength medium (see Appendix 1) can be used for washing based on the intended use of the zoospores. Repeat this wash step a total of 3 times, being careful to not allow cells to dry out. After the final wash, add $10 \mathrm{ml}$ of fresh liquid (the same used for the wash steps) to the flask, and check to ensure that nearly all zoospores have been removed. Only a few swimming zoospores should be visible when the flask is examined under an inverted microscope.

Return the flask to $15^{\circ} \mathrm{C}$ for $2 \mathrm{~h}$ to allow for fresh zoospores to be released. The specific incubation time depends on how closely age-matched the population needs to be; in general, longer incubations result in a higher number of less tightly age-matched zoospores. After incubating, collect the newly released zoospores and, if necessary, centrifuge at $2500 \times g$ (i.e. relative centrifugal force; rcf) for $5 \mathrm{~min}$ to pellet cells and resuspend for desired zoospore concentration.

\subsection{Harvesting zoospores from solid medium}

Zoospores can also be harvested from Bsal grown on solid medium (see Section 3.3). Typically, plates are ready for harvesting 5 to $6 \mathrm{~d}$ after inoculation. To determine whether an agar plate is ready for harvesting, examine it under a microscope (inverted or compound) turned with agar side up. If large clumps of sporangia and active swimming zoospores are visible using a 10× objective (Fig. 3), the plate can be used for zoospore harvesting. 
To stimulate zoospore release from sporangia, flood the plate with 1 to $2 \mathrm{ml}$ of liquid medium and incubate at $15^{\circ} \mathrm{C}$ for $30 \mathrm{~min}$. TGhL medium, Nanopure water, Provosoli medium, and Bonner's salts pre-chilled to $15^{\circ} \mathrm{C}$ (see Appendix 1) are all acceptable for flooding plates, depending on the intended use of the zoospores. After $30 \mathrm{~min}$, check the plate to see if sufficient zoospores have been released. If so, add an additional $1 \mathrm{ml}$ of the chosen medium to the plate, pipetting the liquid over the plate several times before transferring into a sterile tube. Multiple rounds of plate flooding and collection can maximize zoospore collection from the same plate, although this may dilute the sample. Collected zoospores can be centrifuged at $2500 \times g$ rcf for $5 \mathrm{~min}$ and resuspended in the appropriate volume of medium or buffer for downstream applications. To remove remaining sporangia, the resuspended zoospores can be filtered (see Section 4.4).

\subsection{Filtering zoospores}

After harvesting zoospores from liquid or solid medium, some laboratories also filter zoospores to further remove thalli and sporangia, particularly inoculum for animal challenge experiments (e.g. Carter et al. 2019). The collected zoospores are passed through a Büchner funnel lined with Grade 1 Whatman filter paper or $20 \mu$ m nylon mesh (previously autoclaved). Because Whatman filter paper can absorb liquid medium along with zoospores, we recommend using nylon mesh for filtering volumes less than $2 \mathrm{ml}$.

\subsection{Counting zoospores}

For many experiments, including estimating the lethal dose $\left(\mathrm{LD}_{50}\right)$, it is helpful to start with a known concentration or number of cells. The most reproducible way to count cells is to count zoospores, as each zoospore represents 1 colony-forming unit, while sporangia can, in principle, give rise to many colonies. We recommend using a hemocytometer (for an introduction to hemocytometer use, see Absher 1973) and a 40× objective. Zoospores swim quickly and make accurate counting difficult. Therefore, we typically fix zoospores prior to counting using Lugol's iodine (1:100 dilution) that stains cell membranes, allowing greater contrast under the microscope. Fixation also reduces the likelihood of contaminating lab surfaces with live zoospore cultures. For studies where zoospore concentration is important, concen- tration can be adjusted accordingly using serial dilutions. Viability should then be estimated by adding Trypan blue $(0.4 \%)$ to zoospores (1:2 dilution) and used to differentiate live and dead cells (Stockwell et al. 2010). Additionally, viability assays using methylene blue and MTT (3-(4,5-dimethylthiazol-2-yl)-2,5diphenyltetrazolium bromide) have recently been established for $B d$ and Bsal (Lindauer et al. 2019, Webb et al. 2019). Flow cytometry is another technique that can be used to count zoospores and estimate viability, although a protocol for Bsal zoospores has not yet been developed.

\section{ISOLATION OF Bsal FROM INFECTED TISSUE}

Bsal can be isolated from infected host tissue using methods described by Martel et al. (2013) as well as by methods developed for Bd (Longcore et al. 1999, Cook et al. 2018, Fisher et al. 2018, Waddle et al. 2018). Tissues used for culturing should be collected from areas with prevalent or suspected Bsal colonization such as ulcers or highly keratinized toe tips. Ideally, tissues should be collected from an infected animal directly after euthanasia before tissues are overrun with bacterial growth. If possible, collect several tissue samples $\sim 1 \times 1 \mathrm{~mm}$ from each animal to maximize the likelihood of successful isolation. Tissues should be observed after collection using a compound microscope to verify Bsal infection. Tissues should be dragged through TGhL agar plates containing $200 \mathrm{mg} \mathrm{l}^{-1}$ penicillin and $200 \mathrm{mg} \mathrm{l}^{-1}$ streptomycin antibiotics to remove any bacteria or other fungal species which are present. The clean tissue can now be placed on a new TGhL agar plate and incubated at $15^{\circ} \mathrm{C}$. Observe plates daily and discard contaminated plates. Once motile zoospores are observed ( 3 to $6 \mathrm{~d}$ ), the tissue can be carefully removed from the TGhL plate. The Bsal zoospores and zoosporangia can then be removed using a sterile $25 \mathrm{~cm}$ cell scraper or flamed transfer needle and transferred to a flask of liquid medium. Each culture should be monitored closely thereafter for signs of contamination.

\section{CRYOPRESERVATION}

\subsection{Freezing}

For long-term cryopreservation of Bsal, we have adapted methods developed for Bd (Boyle et al. 2003, Gleason et al. 2007). Because cell health at the time 
of freezing is critical, start with a liquid culture that is actively growing and has plenty of motile zoospores. While we only provide recommendations for cryopreserving mixed cultures, synchronized zoospores have also been successfully revived using this approach. Cryopreservation in $-80^{\circ} \mathrm{C}$ freezers can last for months, and we have recovered $B d$ and $B s a l$ cultures after storage in liquid nitrogen for years.

First, remove zoospores and sporangia from the culture flask. Because sporangia tightly adhere to the walls of TC-treated flasks, use a sterile cell scraper to dislodge sporangia from the flask walls. Transfer the culture to a sterile tube and centrifuge at $2500 \times g \operatorname{rcf}$ for $5 \mathrm{~min}$. To prevent the pelleted cells from swimming back into solution, pour off and discard the supernatant immediately after the centrifuge stops. Resuspend the cell pellet in full strength TGhL culture medium supplemented with $10 \%$ sterile dimethylsulfoxide (DMSO) pre-chilled to $4^{\circ} \mathrm{C}$. Adding $10 \%$ fetal calf serum may increase the number of viable cells but is not strictly necessary.

Aliquot $1 \mathrm{ml}$ of the cell solution into pre-labeled cryovials equipped with gaskets and transfer to an isopropanol container (e.g. 'Mr. Frosty' Sigma cat. no. C1562 or equivalent; note: this is essential) that has been pre-chilled to $4^{\circ} \mathrm{C}$. Place the isopropanol container in $\mathrm{a}-80^{\circ} \mathrm{C}$ freezer for 24 to $48 \mathrm{~h}$. Move the frozen cryovials into liquid nitrogen for long-term storage.

\subsection{Thawing}

To thaw, remove 1 cryovial from liquid nitrogen and swirl in a beaker with lukewarm water (approximately 25 to $35^{\circ} \mathrm{C}$ ), until the contents are just thawed, being careful to keep the lip of the sealed tube above the waterline. Add the thawed sample to $10 \mathrm{ml}$ of culture medium pre-chilled to $15^{\circ} \mathrm{C}$. Using additional medium, rinse any remaining cells from the cryovial and combine. To remove the DMSO, centrifuge the medium-cell mixture at $2500 \times g$ rcf for $5 \mathrm{~min}$, immediately discard the supernatant, and resuspend the cell pellet in $10 \mathrm{ml}$ of culture medium pre-chilled to $15^{\circ} \mathrm{C}$. Transfer the cells to a $25 \mathrm{~mm}^{2} \mathrm{TC}$-treated flask and examine using an inverted microscope. We recommend diluting an aliquot 1:10 into an additional flask and monitoring both to make sure at least one is not overcrowded. Alternatively, thawed cells can be added directly to solid media with $1 \mathrm{ml}$ of sterile water or liquid medium to dilute the DMSO. Incubate the culture(s) at $15^{\circ} \mathrm{C}$ and observe daily. When swimming zoospores are visible, the culture is ready to begin subculturing (see Section 3).

\section{CONCLUSION}

The amphibian chytrid pathogen Bsal poses a significant threat to global biodiversity. The ability to develop the mitigation and conservation strategies required to effectively manage a Bsal outbreak is limited by large gaps in our knowledge about the basic biology of this deadly pathogen. We have provided recommendations for growth and handling to help close these gaps by lowering the barriers for new researchers working with Bsal, and by facilitating the comparison of results from different laboratories. We therefore recommend that researchers follow the procedures outlined here and describe any necessary deviations from these procedures in as much detail as is practical in the 'Materials and Methods' section of the relevant manuscript.

Acknowledgements. We thank Amanda Tokash-Peters for data collection on preliminary growth assays and Dr. Louise Rollins-Smith for helpful discussions. This work was supported by the National Science Foundation (IOS-1827257 to L.F.-L. and 1814520 to M.J.G.).

\section{LITERATURE CITED}

Absher M (1973) Hemocytometer counting. In: Kruse PF Jr, Patterson MK Jr (eds) Tissue culture: methods and applications. Academic Press, New York, NY, p 395-397

Berger L, Speare R, Daszak P, Green DE and others (1998) Chytridiomycosis causes amphibian mortality associated with population declines in the rain forests of Australia and Central America. Proc Natl Acad Sci USA 95: 9031-9036

Boyle DG, Hyatt AD, Daszak P, Berger L and others (2003) Cryo-archiving of Batrachochytrium dendrobatidis and other chytridiomycetes. Dis Aquat Org 56:59-64

Burnett LC, Lunn G, Coico R (2009) Biosafety: guidelines for working with pathogenic and infectious microorganisms. Curr Protoc Microbiol 13:1A.1.1-1A.1.14

Carter ED, Miller DL, Peterson AC, Sutton WB and others (2019) Conservation risk of Batrachochytrium salamandrivorans to endemic lungless salamanders. Conserv Lett 13:e12675

Chatfield MWH, Moler P, Richards-Zawacki CL (2012) The amphibian chytrid fungus, Batrachochytrium dendrobatidis, in fully aquatic salamanders from Southeastern North America. PLOS ONE 7:e44821

Cook KJ, Voyles J, Kenny HV, Pope KL, Piovia-Scott J (2018) Non-lethal isolation of the fungal pathogen Batrachochytrium dendrobatidis (Bd) from amphibians. Dis Aquat Org 129:159-164

Coté RJ (2001) Aseptic technique for cell culture. Curr Protoc Cell Biol 00:1.3.1-1.3.10

Fisher MC, Ghosh P, Shelton JMG, Bates K and others (2018) Development and worldwide use of non-lethal, and minimal population-level impact, protocols for the isolation of amphibian chytrid fungi. Sci Rep 8:7772

Fritz-Laylin LK, Lord SJ, Mullins RD (2017) WASP and 
SCAR are evolutionarily conserved in actin-filled pseudopod-based motility. J Cell Biol 216:1673-1688

* Garner TWJ, Schmidt BR, Martel A, Pasmans F and others (2016) Mitigating amphibian chytridiomycoses in nature. Philos Trans R Soc B 371:20160207

Gleason FH, Mozley-Standridge SE, Porter D, Boyle DG, Hyatt AD (2007) Preservation of Chytridiomycota in culture collections. Mycol Res 111:129-136

*Gower DJ, Doherty-Bone T, Loader SP, Wilkinson M and others (2013) Batrachochytrium dendrobatidis infection and lethal chytridiomycosis in caecilian amphibians (Gymnophiona). EcoHealth 10:173-183

* Gray MJ, Lewis JP, Nanjappa P, Klocke B and others (2015) Batrachochytrium salamandrivorans: the North American response and a call for action. PLOS Pathogens 11:e1005251

* Jenkinson TS, Betancourt Román CM, Lambertini C, Valencia-Aguilar A and others (2016) Amphibian-killing chytrid in Brazil comprises both locally endemic and globally expanding populations. Mol Ecol 25:2978-2996

Kilpatrick AM, Briggs CJ, Daszak P (2010) The ecology and impact of chytridiomycosis: an emerging disease of amphibians. Trends Ecol Evol 25:109-118

Klocke B, Becker M, Lewis J, Fleischer RC and others (2017) Batrachochytrium salamandrivorans not detected in US survey of pet salamanders. Sci Rep 7:13132

* Laking AE, Ngo HN, Pasmans F, Martel A, Nguyen TT (2017) Batrachochytrium salamandrivorans is the predominant chytrid fungus in Vietnamese salamanders. Sci Rep 7:44443

Langhammer PF, Lips KR, Burrowes PA, Tunstall T, Palmer CM, Collins JP (2013) A fungal pathogen of amphibians, Batrachochytrium dendrobatidis, attenuates in pathogenicity with in vitro passages. PLOS ONE 8:e77630

* Lindauer A, May T, Rios-Sotelo G, Sheets C, Voyles J (2019) Quantifying Batrachochytrium dendrobatidis and Batrachochytrium salamandrivorans viability. EcoHealth 16: 346-350

Lips KR (2016) Overview of chytrid emergence and impacts on amphibians. Philos Trans R Soc B 371:20150465

KLongcore JE, Pessier AP, Nichols DK (1999) Batrachochytrium dendrobatidis gen. et sp. nov., a chytrid pathogenic to amphibians. Mycologia 91:219-227

Martel A, Spitzen-van der Sluijs A, Blooi M, Bert W and others (2013) Batrachochytrium salamandrivorans sp. nov. causes lethal chytridiomycosis in amphibians. Proc Natl Acad Sci USA 110:15325-15329

Martel A, Vila-Escale M, Fernández-Giberteau D, MartinezSilvestre A and others (2020) Integral chain management of wildlife diseases. Conserv Lett 13:e12707

Morgan JAT, Vredenburg VT, Rachowicz LJ, Knapp RA and others (2007) Population genetics of the frog-killing fungus Batrachochytrium dendrobatidis. Proc Natl Acad Sci USA 104:13845-13850

* Neftel KA, Hübscher U (1987) Effects of $\beta$-lactam antibiotics on proliferating eucaryotic cells. Antimicrob Agents Chemother 31(11):1657-1661

*Nygaard UH, Niehues H, Rikken G, Rodijk-Olthuis D, Schalkwijk J, van den Bogaard EH (2015) Antibiotics in cell culture: friend or foe? Suppression of keratinocyte growth and differentiation in monolayer cultures and 3D skin models. Exp Dermatol 24:964-965

O'Hanlon SJ, Rieux A, Farrer RA, Rosa GM and others (2018) Recent Asian origin of chytrid fungi causing global amphibian declines. Science 360:621-627
Piotrowski JS, Annis SL, Longcore JE (2004) Physiology of Batrachochytrium dendrobatidis, a chytrid pathogen of amphibians. Mycologia 96:9-15

* Refsnider JM, Poorten TJ, Langhammer PF, Burrowes PA, Rosenblum EB (2015) Genomic correlates of virulence attenuation in the deadly amphibian chytrid fungus, Batrachochytrium dendrobatidis. G3 Genes Genomes Genet 5:2291-2298

Ryu AH, Eckalbar WL, Kreimer A, Yosef N, Ahituv N (2017) Use antibiotics in cell culture with caution: genome-wide identification of antibiotic-induced changes in gene expression and regulation. Sci Rep 7:7533

Sabino-Pinto J, Veith M, Vences M, Steinfartz S (2018) Asymptomatic infection of the fungal pathogen Batrachochytrium salamandrivorans in captivity. Sci Rep 8: 11767

* Scheele BC, Pasmans F, Skerratt LF, Berger L and others (2019) Amphibian fungal panzootic causes catastrophic and ongoing loss of biodiversity. Science 363:1459-1463

* Schloegel LM, Toledo LF, Longcore JE, Greenspan SE and others (2012) Novel, panzootic and hybrid genotypes of amphibian chytridiomycosis associated with the bullfrog trade. Mol Ecol 21:5162-5177

Stegen G, Pasmans F, Schmidt BR, Rouffaer LO and others (2017) Drivers of salamander extirpation mediated by Batrachochytrium salamandrivorans. Nature 544:353-356

* Stockwell MP, Clulow J, Mahony MJ (2010) Efficacy of SYBR 14/propidium iodide viability stain for the amphibian chytrid fungus Batrachochytrium dendrobatidis. Dis Aquat Org 88:177-181

*Van Rooij P, Martel A, Haesebrouck F, Pasmans F (2015) Amphibian chytridiomycosis: a review with focus on fungus-host interactions. Vet Res 46:137

Van Rooij P, Pasmans F, Coen Y, Martel A (2017) Efficacy of chemical disinfectants for the containment of the salamander chytrid fungus Batrachochytrium salamandrivorans. PLOS ONE 12:e0186269

*Voyles J, Johnson LR, Briggs CJ, Cashins SD and others (2014) Experimental evolution alters the rate and temporal pattern of population growth in Batrachochytrium dendrobatidis, a lethal fungal pathogen of amphibians. Ecol Evol 4:3633-3641

*Waddle AW, Sai M, Levy JE, Rezaei G, van Breukelen F, Jaeger JR (2018) Systematic approach to isolating Batrachochytrium dendrobatidis. Dis Aquat Org 127:243-247

Watts A, Olson D, Harris R, Mandica M (2019) The deadly amphibian Bsal disease: how science-management partnerships are forestalling amphibian biodiversity losses. Science Findings 214. U.S. Department of Agriculture, Pacific Northwest Research Station, Portland, OR

WWebb RJ, Berger L, Skerratt LF, Roberts AA (2019) A rapid and inexpensive viability assay for zoospores and zoosporangia of Batrachochytrium dendrobatidis. J Microbiol Methods 165:105688

*Woodhams DC, Alford RA (2005) Ecology of chytridiomycosis in rainforest stream frog assemblages of tropical Queensland. Conserv Biol 19:1449-1459

WWodhams DC, Barnhart KL, Bletz MC, Campos AJ and others (2020) Batrachochytrium: biology and management of amphibian chytridiomycosis. eLS, John Wiley \& Sons, Chichester

Yuan Z, Martel A, Wu J, Van Praet S, Canessa S, Pasmans F (2018) Widespread occurrence of an emerging fungal pathogen in heavily traded Chinese urodelan species. Conserv Lett 11:e12436 
Appendix 1. Liquid media formulations

After adding each ingredient listed below, bring the volume up to 11 with deionized water $\left(\mathrm{diH}_{2} \mathrm{O}\right)$. Autoclave all mixtures before use and/or storage. Liquid media can be stored at $4^{\circ} \mathrm{C}, 15^{\circ} \mathrm{C}$, or room temperature but should be brought to $15^{\circ} \mathrm{C}$ prior to being used for culturing.

\section{Full-strength TGhL (1 l): \\ $16 \mathrm{~g}$ tryptone \\ 4 g gelatin hydrolysate \\ $2 \mathrm{~g}$ lactose}

\section{Half-strength TGhL (1 l): $8 \mathrm{~g}$ tryptone \\ $2 \mathrm{~g}$ gelatin hydrolysate \\ $1 \mathrm{~g}$ lactose}
Full-strength $1 \%$ tryptone (1 l): $10 \mathrm{~g}$ tryptone

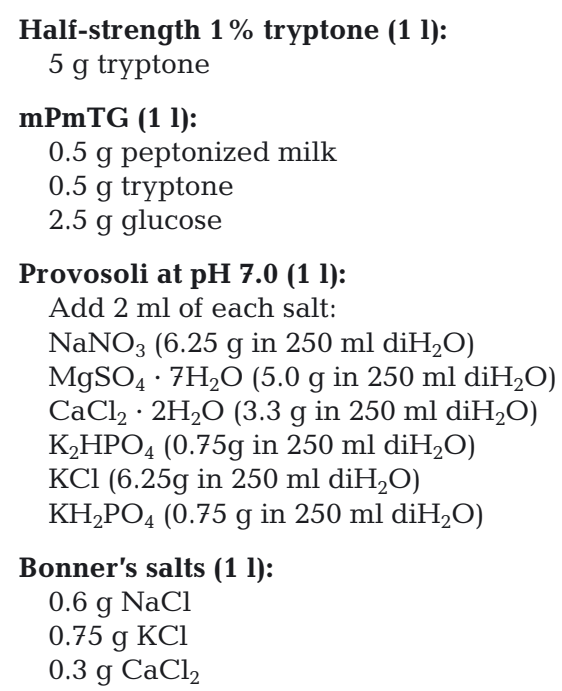

Half-strength $1 \%$ tryptone (1 1): $5 \mathrm{~g}$ tryptone

\section{mPmTG (1 l):}

$0.5 \mathrm{~g}$ peptonized milk

$0.5 \mathrm{~g}$ tryptone

$2.5 \mathrm{~g}$ glucose

\section{Provosoli at pH 7.0 (1 l):}

Add $2 \mathrm{ml}$ of each salt:

$\mathrm{NaNO}_{3}\left(6.25 \mathrm{~g}\right.$ in $\left.250 \mathrm{ml} \mathrm{diH}{ }_{2} \mathrm{O}\right)$

$\mathrm{MgSO}_{4} \cdot 7 \mathrm{H}_{2} \mathrm{O}\left(5.0 \mathrm{~g}\right.$ in $\left.250 \mathrm{ml} \mathrm{diH} \mathrm{H}_{2} \mathrm{O}\right)$

$\mathrm{CaCl}_{2} \cdot 2 \mathrm{H}_{2} \mathrm{O}\left(3.3 \mathrm{~g}\right.$ in $\left.250 \mathrm{ml} \mathrm{diH} \mathrm{d}_{2} \mathrm{O}\right)$

$\mathrm{K}_{2} \mathrm{HPO}_{4}\left(0.75 \mathrm{~g}\right.$ in $\left.250 \mathrm{ml} \mathrm{diH} \mathrm{O}_{2} \mathrm{O}\right)$

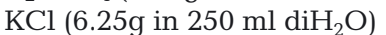

$\mathrm{KH}_{2} \mathrm{PO}_{4}\left(0.75 \mathrm{~g}\right.$ in $\left.250 \mathrm{ml} \mathrm{diH}{ }_{2} \mathrm{O}\right)$

\section{Bonner's salts (1 l):}

$0.6 \mathrm{~g} \mathrm{NaCl}$

$0.75 \mathrm{~g} \mathrm{KCl}$

$0.3 \mathrm{~g} \mathrm{CaCl}_{2}$

Editorial responsibility: Stephen Feist, Weymouth, UK
Appendix 2. Solid media

Prepare TGhL (full or half-strength) following the recipes for liquid media in Appendix 1. Add $10 \mathrm{~g}$ of biological grade agar per $1 \mathrm{l}$ of liquid medium. Autoclave. In general, $250 \mathrm{ml}$ of the agar-TGhL medium generates approximately 20 plates $(60 \mathrm{~mm})$. Plates can be stored at $4^{\circ} \mathrm{C}$ for several months but should be brought to $15^{\circ} \mathrm{C}$ prior to being used for culturing.

If using antibiotics, it is important that autoclaved agar-TGhL medium is first cooled to $60^{\circ} \mathrm{C}$. Even cooling can be achieved within a water-bath set to $45^{\circ} \mathrm{C}-60^{\circ} \mathrm{C}$.

Appendix 3. Antibiotics

\section{Stock antibiotics for liquid media:}

Individually, combine each antibiotic with $5 \mathrm{ml}$ nanopure water:

$0.5 \mathrm{~g}$ ampicillin sodium salt $\left(371.39 \mathrm{~g} \mathrm{~mol}^{-1}\right)$

$0.625 \mathrm{~g}$ streptomycin sulfate $\left(1457.39 \mathrm{~g} \mathrm{~mol}^{-1}\right)$

Because antibiotics are destroyed by autoclaving, use a sterile $0.2 \mu \mathrm{m}$ cellulose acetate syringe to filter each antibiotic into a sterile tube to sterilize. Aliquot sterilized stock mixtures and store at $-20^{\circ} \mathrm{C}$. Prior to using, thaw aliquots at room temperature and use a sterile pipet to add $10 \mu \mathrm{l}$ of each stock mixture per $10 \mathrm{ml}$ of liquid medium.

\section{Antibiotics for solid media:}

Dissolve $0.1 \mathrm{~g}$ of ampicillin sodium salt (371.39 $\left.\mathrm{g} \mathrm{mol}^{-1}\right)$ and $0.1 \mathrm{~g}$ of streptomycin sulfate $\left(1457.39 \mathrm{~g} \mathrm{~mol}^{-1}\right)$ in $2 \mathrm{ml}$ nanopure water. Sterilize by filtering through a $0.2 \mu \mathrm{m}$ cellulose acetate syringe filter. Add $1 \mathrm{ml}$ prepared antibiotics per $500 \mathrm{ml}$ of autoclaved solid medium that has been cooled to $60^{\circ} \mathrm{C}$. Gently swirl to mix and pour plates as normal.

Submitted: October 7, 2019; Accepted: April 22, 2020

Proofs received from author(s): May 31, 2020 